\title{
The Kimbanguist Hospital at Kinshasa, Zaire
}

\author{
Zvi Stern, Eli Mor
}

Hadassah Medical Organization, Box 12000, IL-91 120, Jerusalem, Israel

Zvi Stern, MD, director of Hadassah hospital

Eli Mor, project administrator

BrMed f 1990;301:1437-8

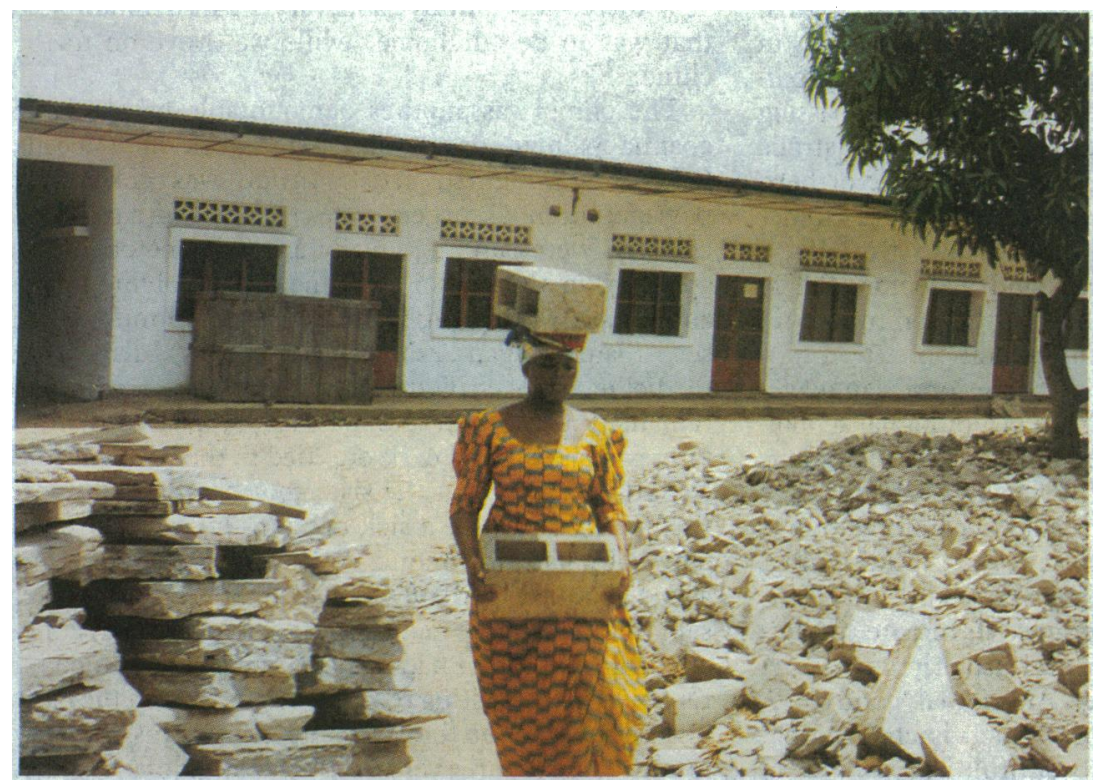

Women participated in construction work, while others provided a hot meal for the volunteers each day

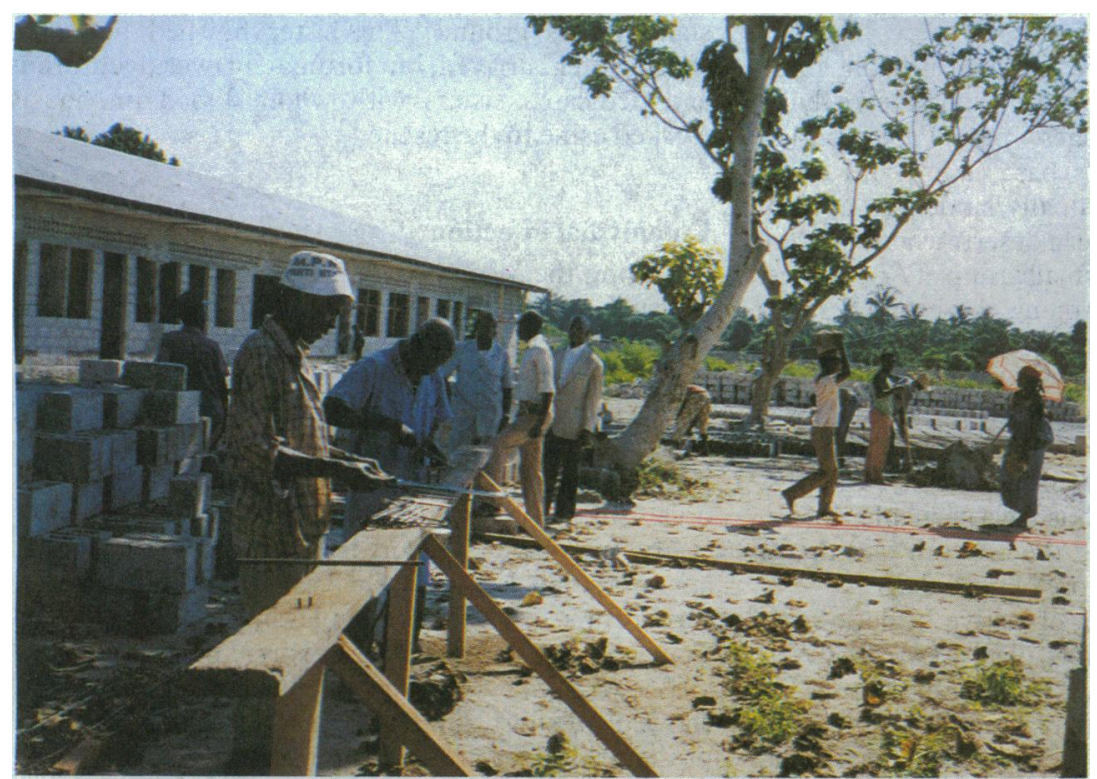

The enthusiasm and commitment of the volunteers made it possible to get the hospital working in such a short time tion, the district has inadequate water supplies and ge facilies, and until the hospital was buil ferved by only a few dispersed

The Kimbanguist Church is a Catholic church established in the 1960s by Priest Simone Kimbange. It has about four million worshippers in Zaire (out of a total population of about 35 million) and another
In the early 1980s the Kimbanguist Church in Zaire decided to establish a hospital in the Kimbanseke area of Kinshasa, the capital. Kimbanseke is one of the to growth rate of $3 \%$. Although subject to rapid urbanisaForeign Affairs. The overall budget for the project was $\$ 2525000$, out of which USAID financed \$1 500000 for construction and equipment. Hadassah Israel was responsible for constructing, equipping, and initially operating the hospital.

When work restarted within the 47000 square metres of open undefined space allocated for the hospital one building was functioning as a maternity department of 30 beds, and there were two partially constructed buildings with no electricity, sewerage, or water supply. The other buildings had only structural walls, shaky floors, and no foundations, and another building had only a basic foundation and partial walls. The area was totally covered with sand; during each rainfall the hospital area became a pool of water.

As the budget was small and limited it was decided to construct the hospital with a volunteer workforce. The entire internal furnishings, including beds, closets, tables, chairs, laboratory work counters, storage space, and all carpentry work, were completed by the hospital's own employees. The volunteers of the Kimbanguist church involved in construction came from all the areas of Kinshasa. Others came from all over Zaire and some from Europe. About 1000 volunteers participated in the construction work, including children, women (even pregnant women and women with babies on their backs), students, schoolchildren, and professionals such as doctors, nurses, and lawyers. Many of the church's younger members volunteered at night, after their regular work, so that construction continued without interruption, 24 hours a day, seven days a week, for a full year.

On 21 May 1988 the hospital opened to the public. Within three months the overall occupancy rate reached $80 \%$, being greatest in the maternity department $(140 \%)$ and the surgical wards $(120 \%)$. The hospital runs several outpatient clinics and also runs programmes for vaccination, growth and development, family planning, antenatal care, nutrition, rehabilitation, and public health. The laboratories offer biochemistry, haematology, serology, and bacteriology testing, and a blood bank provides basic needs and testing for HIV. There is also a computerised statistical reporting system, and a medical library is being developed. Since May 1988 the pharmacy department, radiology department, and the laboratories have had budgetary autonomy.

To attract patients to the hospital Hadassah's administrator met the owners of many large factories nearby while the hospital was still being built and 
offered modern medical services for their employees and families. The factory would provide an empty space that the hospital would equip and convert into an occupational health clinic. The hospital was then responsible for providing a doctor and a nurse who could give first aid treatment to the employees. All laboratory tests were completed at the Kimbanguist Hospital, and workers and their families were admitted there when necessary.

What made it possible to complete the hospital's construction and get it working in such a short time was the collaboration of local and international organisations and in particular the enthusiasm and commitment of the volunteers. Each day during construction a hot meal was provided to the volunteers.
Because there was no budget for this, Kimbanguist women from Kinshasa came to the hospital in groups with all the materials necessary to make these meals. The church people also volunteered their vehicles to transport hundreds of workers to and from the construction site. The enthusiasm was also enhanced by Son Eminence Dianganda Kontima, the spiritual father of the church, who would arrive at the construction site several times a week, both during the day and at night. His presence attracted additional volunteers, and at times there were more than 1500 volunteers on the site. The entire construction was completed manually -in song and in happiness.

We thank J Allhole for her help and advice.

\section{Medicine in the outback}

\section{Bernhard Ostberg}

\section{The advertisement}

A notice appeared in the Australian in May 1988. Medical Officer required for an independent aboriginal controlled Health Service based at Walungurru $520 \mathrm{~km}$ west north west of Alice Springs. It cares for approximately 600 Pintupi people over a vast area encompassing the community of Kiwirrkurra in Western Australia and also numerous outstations in both the Northern Territory and Western Australia. The Pintupi Homelands Health Service employs six health workers, a traditional healer, two sisters, and a doctor. Policy decisions are made by the Health Committee in consultation with staff and administration.

The community-English is a second language. Alcohol is rigidly banned. There is a bilingual school. There is a store and a Lutheran church. A mail plane arrives every Wednesday and Friday. Communication is by radio telephone. Health staff accommodation is basic, being demountables with air conditioning, cooking facilities, toilet, and shower.

Qualifications - Work experience in remote, preferably Aboriginal, communities and also primary care. A commitment to work under Aboriginal control. A willingness to undertake work which is challenging, wide ranging, and hard in a beautiful, isolated area of the western desert.

\section{The arrival}

Some correspondence and a few difficult radio telephone conversations later my wife and I were flying along the Macdonnell Ranges, past Papunya and Ilpilla, the site of Lasseter's base camp, and on to Kintore. The small aircraft finally landed on a dusty ochre-red airstrip in the western desert, where we were met by a sister, Dr George, a small group of Aborigines, and a large pack of dogs. Among the group I saw a young Aboriginal woman with a papilloma the size of a cherry in her lip, and I wondered why it hadn't been removed. It was in fact a plug of tobacco, which it was common practice for the Aborigines to chew and then to store by holding it in the corner of their mouths. The tobacco is mixed with the ash of a particular shrub, and a white person who used the mixture said that it had properties resembling those of marijuana.

Dr George, the Ngunkara or native healer, was a stocky Aboriginal with a short black beard and was dressed in only a red singlet and navy shorts. After the radiator in the old Toyota had been refilled with water we left for the settlement of small concrete houses and tin humpies that were settled among years of accumulated rubbish. My wife and the large amount of luggage, books, and medical equipment were left at a very dirty, very untidy, and very small demountable that was to be our home, while we drove on to the clinic.

The clinic was another demountable with a large goanna painted on its side-the work of a locally famous Walungurru artist. Inside was chaos: the passage and small surgery were crammed with patients, children were running crazily around, one child was spinning in the doctor's dilapidated revolving chair, and music was blaring from the radio communication set. Sister began examining patients, dispensing medicine, and syringing ears. Dr George, who had remained behind in the passage, appeared with a kidney dish of blood to be emptied in the wash basin. I looked inquiringly at the sister but her only response was to ask me to see a sick baby in the waiting room. The baby had pneumonia so I ordered penicillin and asked about the patient who had vomited blood. Sister said that Dr George had sucked the blood therapeutically from the baby I had just examined. Incredulous, I returned to the waiting room and re-examined the baby but could find no break in its skin. This was my introduction to three very unusual months of medicine. The doctor, whom I was relieving, had been 20 months in the community and was devoted to the Aborigines despite having been beaten on several occasions for standing his ground. The sister finished her term shortly after I arrived, but fortunately two adventurous and dedicated sisters with whom I had previously worked came to the rescue.

\section{Chlamydial infection}

During the second week it occurred to me that the unusual prevalence of upper respiratory infection might be due to the same organism that causes endemic trachoma - that is, Chlamydia trachomatis. Nasal infection is probably primary with later spread to the eyes, ears, and bronchi. Should the primary infection occur in the eyes then the nasolacrimal duct would give the organism easy access to the respiratory tract.

My interest in chlamydia prompted me to look among the books on the shelves of the clinic, where I was surprised to find some relevant texts. The Royal College of Ophthalmologists' report National Trachoma and Eye Health Programme states: "The findings showed, in short, a marked relationship between the presence of respiratory disease, as conservatively defined, and such conditions as otitis media and nasal discharge, as well as follicular trachoma."' In the 